\section{Coronary and peripheral artery aneurysms in a patient with cutaneous T-cell lymphoma}

A 48-year-old man was referred to our institution for acute limb ischaemia. He had been diagnosed with cutaneous T-cell lymphoma, so-called mycosis fungoides by gene rearrangement analysis of skin biopsy samples 9 years ago. He had received prednisolone $5 \mathrm{mg}$ daily and phototherapy for mycosis fungoides. Although allergy symptoms and signs including asthma, peripheral neuropathy and glomerulonephritis had not been evident, his rashes had been worsening in his face and abdomen for a few months.

On examination, enhanced CT revealed thrombotic occlusion in the left posterior tibial artery (figure 1A, B) and multiple aneurysms of various systemic peripheral vascular beds, including those of posterior tibial artery, ulnar artery and so on. Laboratory test showed slight elevation of $\mathrm{C}$ reactive protein $(0.40 \mathrm{mg} / \mathrm{dL})$ and hypereosinophilia (leucocyte count $5.5 \times 10^{9} / \mathrm{L}$, eosinophil 19.4\%), whereas antineutrophil cytoplasmic antibody (ANCA) was negative. Cardiac MRI showed late gadolinium enhancement in endocardium side and $18 \mathrm{~F}$-fluorodeoxyglucose positron emission tomography demonstrated abnormal uptake in interventricular septum (figure 1C-E). Coronary angiography revealed the asymptomatic development of multiple septal branch aneurysms (figure 2A). End-myocardial biopsy showed severe fibrosis without infiltration of inflammatory cell nor granulomas. Biopsy of the affected ulnar artery demonstrated abundant infiltration of eosinophils and CD4-positive $\mathrm{T}$ cells and no evidence of necrotising vasculitis (figure $2 \mathrm{~B}-\mathrm{D}$ ).

Vasculitis with hypereosinophilia is primarily recognised in eosinophilic granulomastosis with polyangiitis (EGPA) that preferentially affects certain organ systems including the airways, peripheral nerves, heart, kidney and gastrointestinal tract. Given that cardiac involvement is reported to be more frequent in patients with EGPA who are ANCA-negative, EGPA is one of differential diagnosis in this case. ${ }^{1}$ However, lack of typical clinical manifestations of the affected organs, no evidence of a histological necrotising vasculitis and an abundance of eosinophils in this case could advocate other kinds of vasculitis. According to previous reports, angiolymphoid hyperplasia with eosinophilia (ALHE) associated with mycosis fungoides is characterised by the proliferation of blood vessel with infiltration of lymphocyte and eosinophils. ${ }^{2} 3$ This case corresponding to these previous reports suggests cardiac involvement in ALHE with mycosis fungoides. We emphasise the need for an increasing awareness of systemic cardiovascular disorder in patients with mycosis fungoides.
Figure 1 Enhanced CT of the left infrapopliteal artery (A). Yellow arrow showing left posterior tibial aneurysm with thrombotic occlusion (B). Abnormal uptake in interventricular septum (arrow) shown using 18F-fluorodeoxyglucose positron emission tomography (C). Late gadolinium enhancement cardiac MRI in short-axis (D) and long-axis images (E).

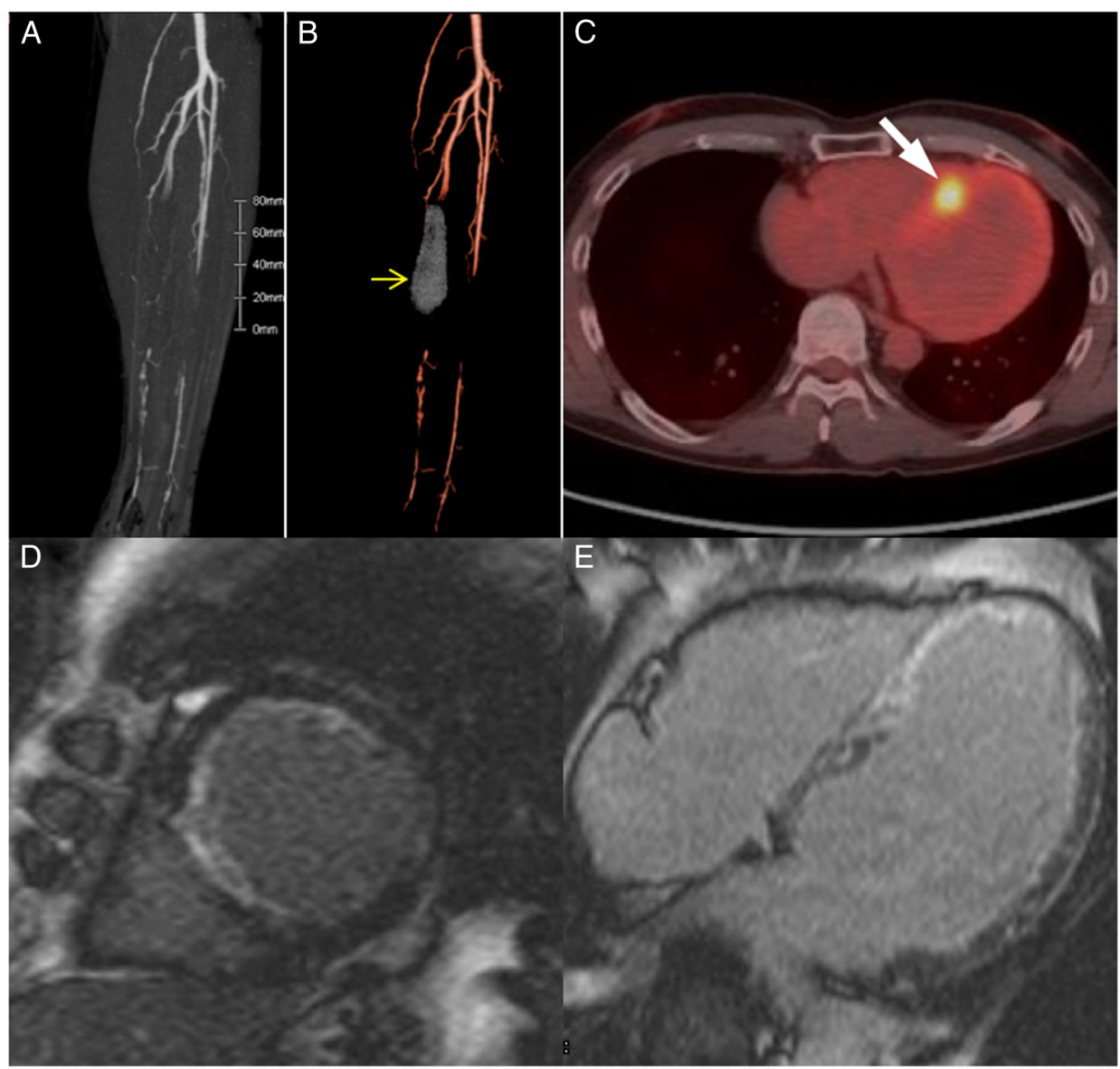



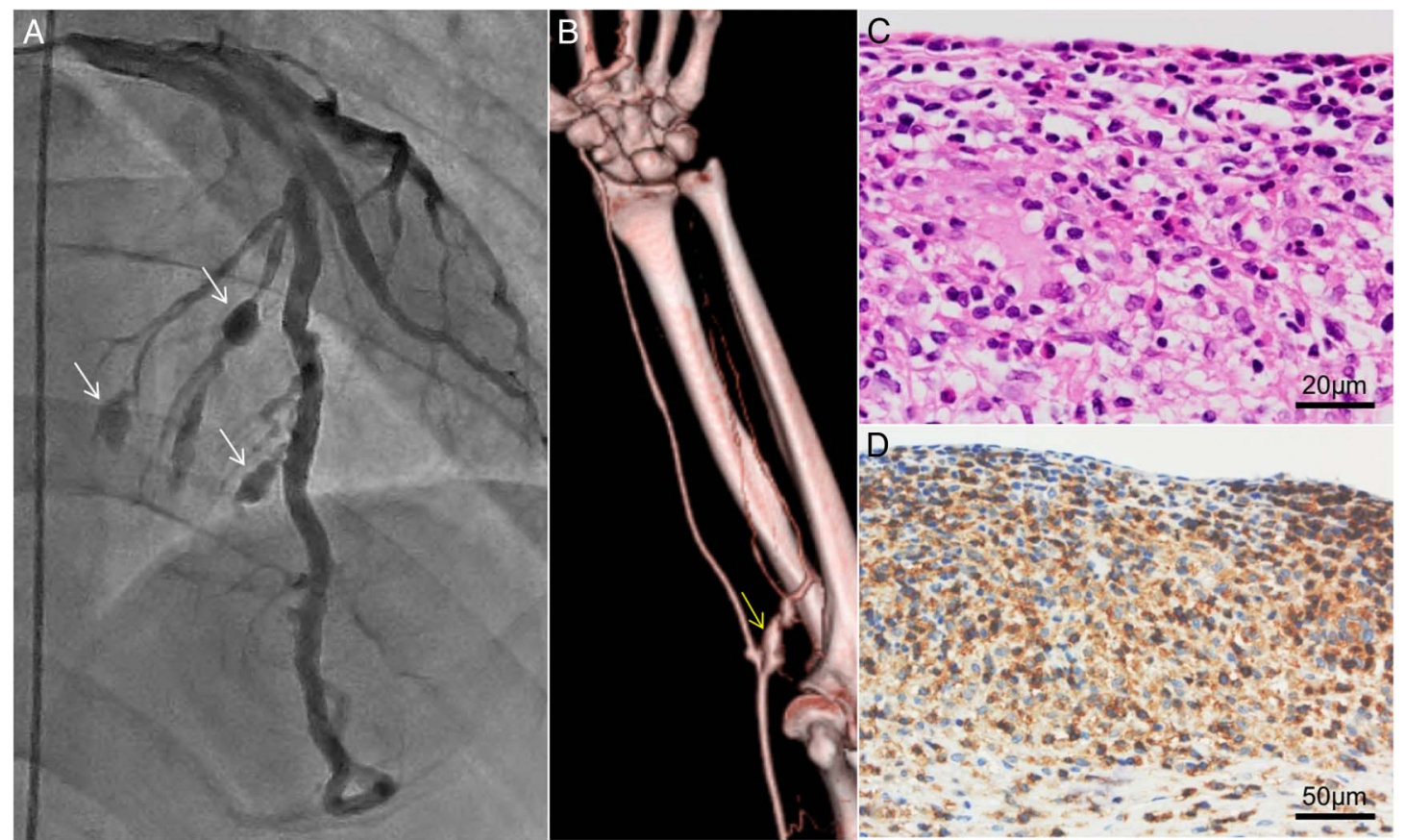

Figure 2 Multiple septal branch aneurysms (arrow) identified by coronary angiography (A). Left ulnar aneurysm (yellow arrow) in enhanced CT (B). Histopathological findings of an ulnar artery aneurysm showing infiltration of eosinophils and lymphocytes (H\&E stain) (C) and CD-4 positive T cells (immunostaining) (D).

\section{Hideki Yasutake, ${ }^{1}$ Yoshihiko Ikeda, ${ }^{2}$ Osami Kawarada ${ }^{1}$}

${ }^{1}$ Department of Cardiovascular Medicine, National Cerebral and Cardiovascular Center, Suita, Osaka, Japan

${ }^{2}$ Department of Pathology, National Cerebral and Cardiovascular Center, Suita, Osaka, Japan

Correspondence to Hideki Yasutake, Department of Cardiovascular Medicine, Osaka University Graduate School of Medicine, Suita, Osaka 565-0871, Japan; yasutake@cardiology.med.osaka-u.ac.jp

Contributors All the authors were involved in the clinical management of the patients. HY drafted, and OK revised the manuscript.

Competing interests None declared.

Patient consent Obtained.

Provenance and peer review Not commissioned; externally peer reviewed.

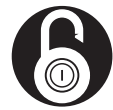

\section{OPEN ACCESS}

Open Access This is an Open Access article distributed in accordance with the Creative Commons Attribution Non Commercial (CC BY-NC 4.0) license, which permits others to distribute, remix, adapt, build upon this work non-commercially, and license their derivative works on different terms, provided the original work is properly cited and the use is non-commercial. See: http://creativecommons.org/ licenses/by-nc/4.0/

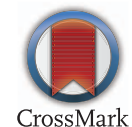

To cite Yasutake H, Ikeda Y, Kawarada 0. Heart Asia 2017:9:25-26. doi:10.1136/ heartasia-2016-010858

Received 12 November 2016

Revised 21 November 2016

Accepted 22 November 2016

Heart Asia 2017;9:25-26. doi:10.1136/heartasia-2016-010858

\section{REFERENCES}

1 Khoury P, Grayson PC, Klion AD. Eosinophils in vasculitis: characteristics and roles in pathogenesis. Nat Rev Rheumatol 2014;10:474-83.

2 Gonzalez-Cuyar LF, Tavora F, Zhao XF, et al. Angiolymphoid hyperplasia with eosinophilia developing in a patient with history of peripheral T-cell lymphoma: evidence for multicentric T-cell lymphoproliferative process. Diagn Pathol 2008;3:22.

3 Kempf W, Haeffner AC, Zepter K, et al. Angiolymphoid hyperplasia with eosinophilia: evidence for a T-cell lymphoproliferative origin. Hum Pathol 2002;33:1023-9. 